\title{
Repeated successive contrast in consummatory behavior with repeated shifts in sucrose concentration
}

\author{
CHARLES F. FLAHERTY, HOWARD C. BECKER, and SUSAN CHECKE \\ Rutgers University, New Brunswick, New Jersey
}

\begin{abstract}
Contrast in consummatory behavior was investigated following repeated shifts from $32 \%$ to 4\% sucrose. In Experiment 1, contrast in licking and in open-field measures of activity occurred following the second and third downshifts. In Experiments $2 a$ and 2b, equivalent contrast effects occurred following the first and second downshifts in sucrose. In Experiment 3, negative contrast remained unabated following nine downshifts in animals shifted between $32 \%$ and $4 \%$ sucrose on alternate days. Similar results were found for five downshifts in animals shifted every 2 days. In both of these latter conditions, positive contrast occurred over the first few shifts and was then lost as the $32 \%$ control group reached asymptote. These data show that repeated negative contrast effects in consummatory behavior are robust and enduring and occur under several different sets of experimental parameters. The results are discussed in terms of reinforcement level and emotional interpretations of contrast effects, and the possibility was suggested that the causal mechanism of contrast changes with repeated shifts.
\end{abstract}

Capaldi and Lynch (1967) reported that a successive negative contrast effect in runway behavior that occurred following a downshift in number of food pellets failed to recur when the animals were downshifted for a second time following a period of return to the initial reward conditions. The reduction of contrast with repeated shifts would be expected from a variety of theoretical positions, including generalization decrement (Capaldi \& Lynch, 1967), adaptation level (Bevan, 1968), and, perhaps, from positions emphasizing the possible role of neophobia in the initial response to the postshift solution (Flaherty, Lombardi, Wrightson, \& Deptula, 1980).

However, negative contrast has been reported following second shifts in both magnitude and delay of reward (Maxwell, Calef, Murray, Shepard, \& Norville, 1976; Shanab, Domino, \& Melrose, 1977), and McCain, Lobb, and Newberry (1976) obtained a negative contrast following a downshift in percentage of reward, but not until the third shift. In a runway study with a constant 15-sec delay of reward, Goomas (1981) found negative contrast in the first and second downshifts in magnitude of reward, but not in four subsequent downshifts. Goomas also reported a positive contrast effect in the second and third upshifts in reward, but not in four subsequent upshifts. McCain and Cooney (1975) also reported a positive contrast effect following a second or a third upshift in reward, but McCain, Lobb, Almand,

This research was supported by a grant from the Rutgers University Research Council. The authors' mailing address is: Department of Psychology, Rutgers University, Busch Campus, New Brunswick, New Jersey 08903. and Leck (1976) found no positive contrast after either the first or second shift in delay of reward.

Thus, there are few, and possibly inconsistent, data concerning the effects of multiple shifts in reward on negative contrast. In all likelihood, the effect of repeated shifts on contrast is a parameter-, and perhaps apparatussensitive phenomenon. The present series of experiments is concerned with the effects of repeated downshifts in one specific situation-the consumption of sucrose solutions. Instrumental behavior is not measured in these studies-many experiments have shown that contrast in instrumental behavior is not obtained when the concentration of sucrose solutions is downshifted (e.g., Flaherty, Riley, \& Spear, 1973; Shanab, France, \& Young, 1975). In addition, a substantial body of data is accumulating regarding the effects of various drugs on consummatory contrast (e.g., Becker \& Flaherty, 1983; Flaherty, 1982). These drug data may provide a useful comparative system for the study and interpretation of repeated contrast effects.

\section{EXPERIMENT 1}

In this experiment, animals were given access to either a $32 \%$ or a $4 \%$ sucrose solution in an open field. The sucrose was available 5 min each day, beginning with the animals' first lick. Previous experiments in this situation have provided evidence of contrast in consummatory responding as well as in some ancillary behaviors such as rearing and in-motion behaviors (Flaherty, Blitzer, \& Collier, 1978; Flaherty, Powell, \& Hamilton, 1979; Flaherty, Troncoso, \& Deschu, 1979). The occur- 
rence of contrast in motion-related ancillary behaviors (but not in grooming) shows that incentive relativity effects a substantial part of the animal's behavioral repertoire, not just consumption. Furthermore, the pattern of behaviors showing contrast is consistent with an interpretation of contrast in terms of emotional responses (cf. Flaherty, 1982; Flaherty et al., 1978).

\section{Method}

Subjects. Twelve 120-day-old naive, male Sprague-Dawleyderived rats, purchased from Charles River, were used as subjects. The rats were maintained at $80 \%$ of their free-feeding weights and housed singly on a 14/10-h light/dark cycle throughout the experiment.

Apparatus. A standard open field $(122 \times 130 \times 30 \mathrm{~cm})$ described in detail elsewhere (Flaherty, Powell, \& Hamilton, 1979; Flaherty, Troncoso, \& Deschu, 1979) was used.

Procedure. The experiment consisted of 5 days of habituation to the open field and three contrast phases, each separated by a 3-day break. Each contrast phase consisted of a preshift period in which half the rats were allowed access to $32 \%$ sucrose and half to $4 \%$ sucrose, and a shift phase in which all rats received $4 \%$ sucrose. Following the first shift, the animals were returned to their original sucrose solutions for a second preshift phase and then shifted again; this cycle was repeated for a third time. Preshift Phase 1 was continued for 12 days, Shift 1 for 6 days, Preshift 2 for 6 days, Shift 2 for 6 days, Preshift 3 for 6 days, and Shift 3 for 3 days.

For 10 days prior to the start of the experiment, while being reduced to their deprivation weights, the rats were handled each day. The basic test procedure consisted of placing the rat in the center of the open field and recording its behavior for a period of $5 \mathrm{~min}$. A time sampling method was used in which every $10 \mathrm{sec}$ a small pilot light would flash and the experimenter would record the rats' behavior as falling into one of the following categories: Wall rearing, open rearing, licking (not relevant during habituation), grooming, motion, stationary, stationary sniffing. These behaviors are more fully defined by Flaherty et al. (1978). In addition, the number of squares traversed and the number of licks made were recorded.

At the end of each test, the animal was weighed and returned to its home cage; the open field was then wiped with a damp sponge. All animals were fed their daily ration $15 \mathrm{~min}$ after the last rat was run. Running order of the shifted and unshifted rats was randomized and changed each day.

The contrast phases differed from the habituation phase in that sucrose was available from a drinking tube located on one wall of the open field. During the contrast phases, the 5-min session started with the rat's first lick on the tube. Sucrose solutions were mixed by weight from commercial-grade cane sugar and tap water. Solutions presented to the animals were always between 1 and 4 days old.

\section{Results}

One rat in the shifted group was dropped from the experiment for failing to be active during the habituation phase. Only three dependent variables-number of licks, squares traversed, and wall rearing-will be considered in this paper. Also, the data from the habituation phase will not be presented in detail. A complete analysis of the habituation period and the effects of sucrose conditions on all the open-field dependent variables in similar experiments is presented elsewhere (Flaherty et al., 1978; Flaherty, Powell, \& Hamilton, 1979; Flaherty, Troncoso, \& Deschu, 1979).

Presented in Figure 1 are the differences in wall rearing, squares traversed, and licks as a function of
SHIFT NUMBER

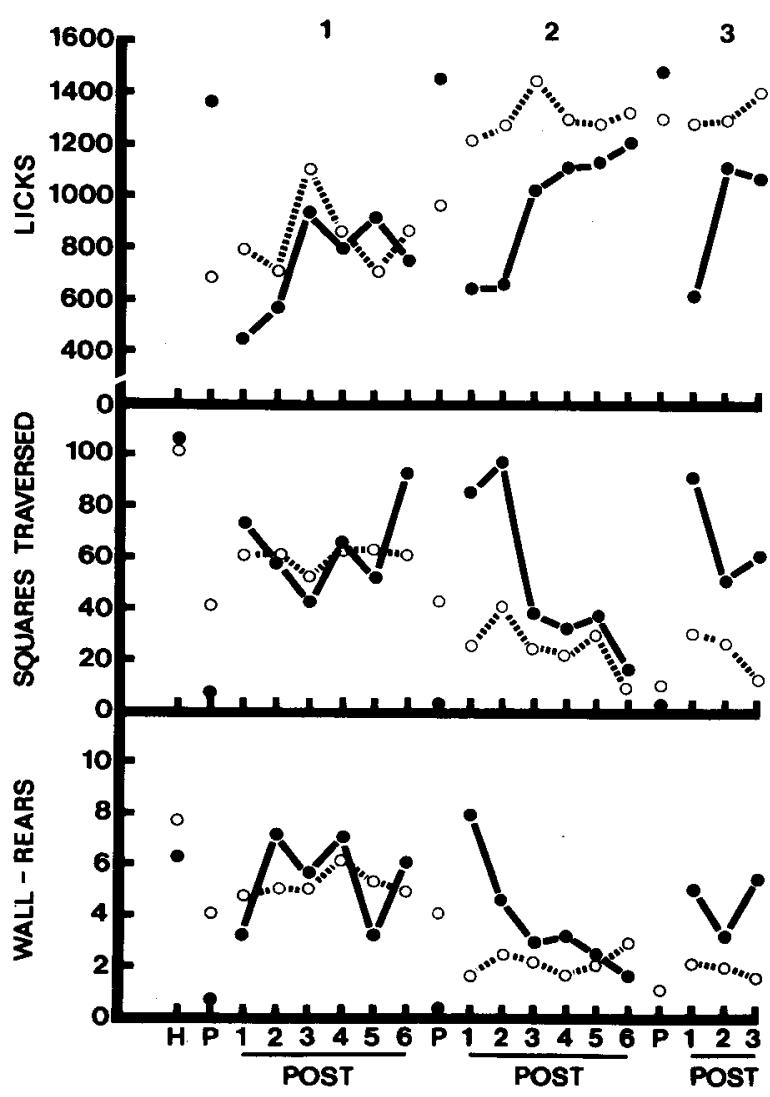

Figure 1. Consummatory and activity behaviors as a function of sucrose condition. The filled-circle solid line represents animals shifted between $32 \%$ and $4 \%$; the open-circle dotted line represents animals maintained on $4 \% . \mathrm{H}=$ terminal habituation phase data, $p=$ terminal preshift data prior to each shift, and "post" = data obtained on each day of the postshift period.

stage of the experiment. There were no reliable group differences at the end of the habituation phase. By the end of the first preshift period, the rats receiving $32 \%$ sucrose were licking more than the $4 \%$ animals $[\mathrm{F}(1,9)$ $=12.16, \mathrm{p}<.01]$; they also crossed fewer squares $[F(1,9)=10.89, p<.01]$ and made fewer wall rears $[F(1,9)=21.26, p<.01]$ than the $4 \%$ animals.

The first downshift in sucrose led to a small numerical contrast in licks on the first postshift day, but analysis of variance indicated no overall contrast $(F<1.00)$ or any interaction between sucrose condition and postshift days $[F(5,44)=1.40, p<.05]$. Other differences apparent in Figure 1 were also not statistically reliable. The return to the original sucrose conditions in the second preshift phase led to a return of all the differences between groups that were reliable in the first preshift phase.

The second shift from $32 \%$ to $4 \%$ sucrose led to substantial negative contrast effects in licks and the two ancillary behaviors. These contrast effects are evidenced by a lower lick rate in the shifted than in the unshifted animals, but a higher level of wall-rearing and in-motion 
behavior by the shifted animals than by the unshifted controls. In terms of licks, the shifted animals remained below the unshifted controls for all 6 postshift days. However, this difference was reliable for only the first 3 of these days [group $X$ day, $F(5,45)=5.09, p<.01$, followed by least significant difference (1sd) tests]. In terms of squares traversed, the contrast was reliable on the first 2 postshift days $[F(5,45)=4.68, p<.01$, followed by lsd tests]. In wall rearing, the contrast was reliable on the 1st postshift day $[\mathrm{F}(5,45)=5.86, \mathrm{p}<.01$, followed by lsd tests].

Over the last 2 days of the third preshift phase, the $32 \%$ group licked more $[F(1,9)=5.41, p<.05]$ and traversed fewer squares $[F(1,9)=21.02, p<.01]$ than the $4 \%$ group. The differences in wall rearing during this phase were not statistically reliable.

The third shift in sucrose concentration led to a negative contrast in lick rate $[F(2,18)=3.80, p<.05]$ that was reliable on the 1st postshift day only. The contrast effect in squares traversed was also reliable $[F(1,9)=$ $6.41, p<.05]$ and did not change reliably across the 3 postshift days [group $X$ day, $F(2,18)=3.17, \mathrm{p}<.05$ ] Finally, the contrast effect for wall rearing was reliable only on the 3 rd postshift day $[F(2,18)=3.66, p<.05$, followed by lsd tests].

\section{Discussion}

The present data indicate that contrast effects in the consumption of sucrose occurred in the last two of three downshifts from $32 \%$ to $4 \%$ sucrose. In addition to the contrast in consumption, contrast effects also occurred in frequency of wall rearing and in squares traversed. Although the simultaneous occurrence of these latter two behaviors is impossible (as defined), they are highly correlated in this apparatus (Meinrath, 1980), and thus both may be taken as indices of activity. The failure of contrast to occur reliably on the first shift in this experiment is probably a chance result, since large contrast effects occurred on the first (and only) shift in earlier experiments with very similar procedures (e.g., Flaherty et al., 1978; Flaherty, Powell, \& Hamilton, 1979; Flaherty, Troncoso, \& Deschu, 1979).

The repeated occurrence of contrast in consum. matory and activity-related behaviors with repeated shifts in sucrose concentration has implications for theoretical interpretations of incentive relativity effects. Before considering these, however, the occurrence of contrast with repeated shifts will be examined under conditions used more frequently than the open field in sucrose contrast work.

\section{EXPERIMENT 2a}

Most of the data available concerning sucrose contrast have been obtained in an apparatus in which the rat is confined in a space much smaller than the open field used in Experiment 1 (e.g., Becker \& Flaherty, 1982; Flaherty et al., 1980; Vogel, Mikulka, \& Spear, 1968). This experiment and the next one were con- cerned with the effects of a second shift in sucrose concentration in this usual confinement situation.

\section{Method}

Subjects. Seven male, naive, Sprague-Dawley rats, purchased from Blue Spruce Farms were used as subjects. The rats, approximately 75 days old at the start of the experiment, were maintained at $82 \%$ of their free-feeding body weights throughout the experiment by being given a single daily feeding. The subjects were housed individually on a 14/10-h light/dark cycle with water continuously available in the home cage.

Apparatus. The subjects were tested in four identical metal cages $(24.5 \times 17.5 \times 18 \mathrm{~cm})$. A $1-\mathrm{cm}$-diam hole was centered $7 \mathrm{~mm}$ above the floor on one side of each of the cages. A graduated cylinder was placed outside the chamber so that the orifice of the drinking spout was centered in the hole flush with the outside wall of the cage. A contact-relay circuit was used to record the licking response.

Procedure. The experiment consisted of two phases. In the first phase, four animals received a $32 \%$ sucrose solution during preshift training (10 days) and then a $4 \%$ sucrose solution for 4 days (postshift trials). After the 4 th postshift day of the first phase of the experiment, these shifted animals were then returned to the $32 \%$ sucrose solution for 10 more days (preshift period of Phase 2). On the 25 th day of the experiment, these animals were again shifted to the $4 \%$ solution for 4 postshift days. The remaining three rats served as unshifted controls, receiving $4 \%$ sucrose throughout the experiment. The animals were allowed $5 \mathrm{~min}$ access to the sucrose solutions, beginning with the first lick. All subjects received ip injections of saline on the 2nd postshift day in each phase of the experiment (Days 12 and 26). These animals were controls for a study investigating ethanol's effects on contrast.

SHIFT I

SHIFT II

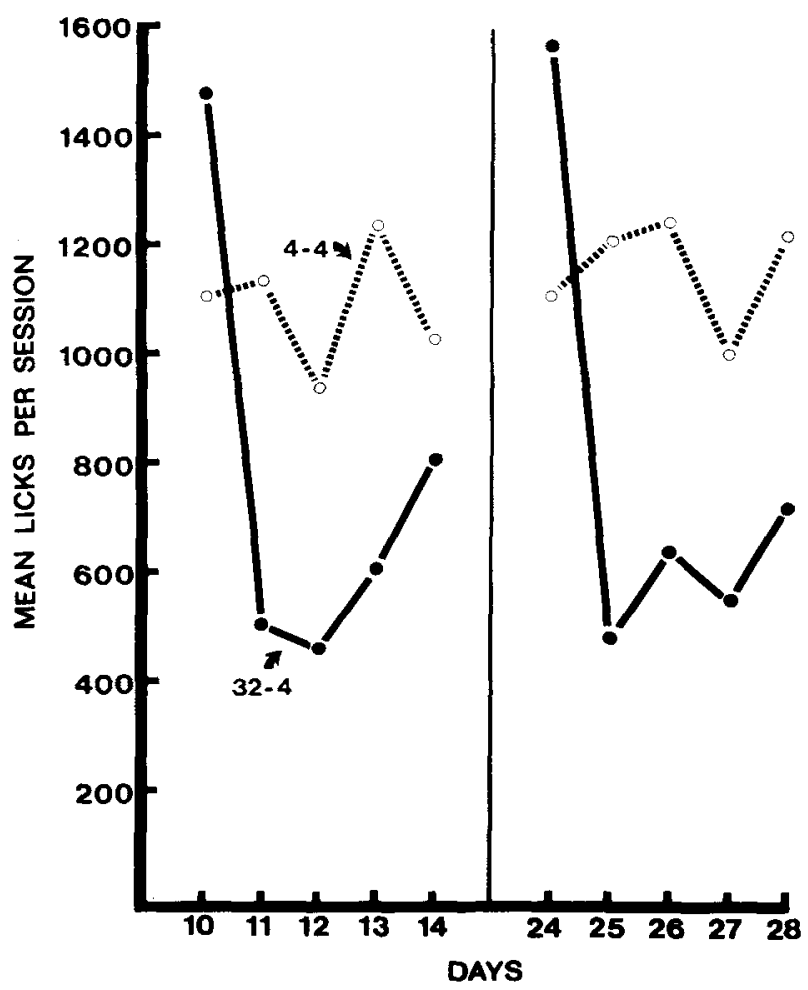

Figure 2. Terminal preshift (Days 10 and 24 ) and daily postshift lick data for each shift. 
Sucrose solutions were prepared by weight (sucrose/sucrose + water) from commercial-grade cane sugar and tap water, $24 \mathrm{~h}$ before each session.

\section{Results}

As can be seen in Figure 2, on the terminal preshift days of both phases (Days 10 and 24), the subjects receiving $32 \%$ sucrose licked more than the controls, maintained on the $4 \%$ solution. In addition, negative contrast was significant (unshifted controls licked reliably more than shifted subjects) on all postshift days for both phases (downshifts) of the experiment. These results were indicated by a significant sucrose concentration $x$ day interaction $[F(4,20)=8.76$, $p<.001]$, followed by lsd tests $(p=.05)$. Lick rates did not differ between the two phases of the experiment for shifted and unshifted subjects, as indicated by a nonsignificant phase $x$ sucrose concentration interaction $[F(1,5)<1]$.

\section{EXPERIMENT 2b}

Experiment $2 b$ was a replication of the previous study, except that there were a larger number of animals and some parametric changes.

\section{Method}

Subjects. Twenty-four naive, male rats of the SpragueDawley strain were used as subjects. The rats, approximately 75 days old at the start of the experiment, were maintained as in the previous experiment.

Apparatus. The apparatus was the same as that in the previous experiment, except that six such chambers were used for testing the subjects.

Procedure. The subjects were divided randomly into shifted and unshifted groups. Shifted animals received $32 \%$ sucrose for 8 preshift days and then $4 \%$ sucrose for 2 postshift days. After a 7-day rest period (when the animals were not run, but were maintained at their deprived weights), these shifted subjects were returned to the $32 \%$ sucrose solution for eight preshift trials in this second phase of the experiment. They were then shifted again to $4 \%$ sucrose for 2 postshift days. The remaining unshifted subjects received the $4 \%$ solution on all experimental days of both phases of the experiment. Subjects received ip injections of saline on either the 1st or 2nd postshift days in each phase of the experiment. In the first phase, saline was administered $2 \mathrm{~h}$ before the testing session; the injections were given $1 / 2 \mathrm{~h}$ prior to the start of the sessions in the second phase of the experiment. These animals were controls for a study investigating the effects of chlorpromazine on contrast. All other aspects of the experiment were similar to those in Experiment 2 a.

\section{Results}

The data are expressed as mean licks per 5-min session and mean proportion licks per session. The proportion measurement was derived by dividing each animal's postshift lick rate by the sum of its terminal preshift and postshift lick rates.

As illustrated in Figure 3, negative contrast occurred on both postshift days (shifted subjects that had had prior experience with $32 \%$ sucrose licked reliably less of

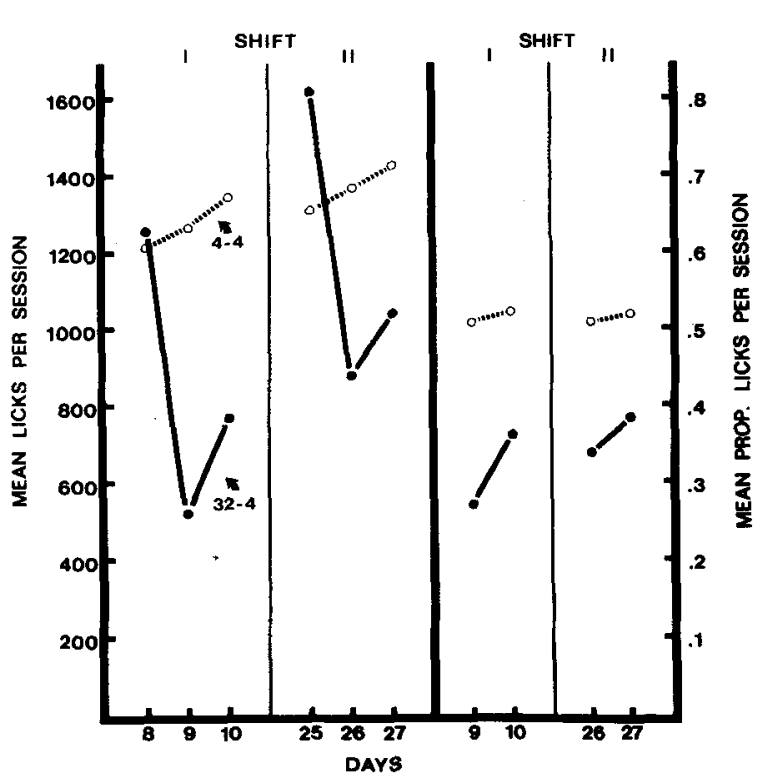

Figure 3. Terminal preshift (Days 8 and 25) and daily postshift lick data for each shift. The right-hand panel presents the postshift data expressed as a proportion of terminal preshift lick frequencies.

the $4 \%$ postshift solution than did unshifted controls that were maintained on $4 \%$ sucrose). This was true across both phases (downshifts) of the experiment, as indicated by a significant sucrose concentration $X$ day interaction $[F(2,44)=70.39, p<.001$, followed by lsd tests, $\mathrm{p}=.05 ; \mathrm{F}(1,22)=8.86, \mathrm{p}<.01$, followed by 1sd tests, $p=.05$, for the licks and proportions data, respec. tively]. Analysis of the licks data also revealed a significant phase $X$ sucrose concentration interaction $[F(1,22)$ $=12.06, p<.01]$. Subsequent analysis indicated that shifted subjects licked reliably more in the second phase of the experiment than in the first (by lsd tests, $p<.05$ ). However, as mentioned above, negative contrast was reliable in both phases of the experiment (by lsd tests, $p=.05$ ). Furthermore, the phase $X$ sucrose concentration interaction was not significant when the data were analyzed as proportions $[F(1,22)=2.90, p>.10]$. This indicates that although shifted subjects licked reliably more in the second phase than in the first, the degree of contrast was not reliably different between phases of the experiment. Unshifted animals did not differ between the two phases of the experiment for either the licks or the proportions analyses.

\section{EXPERIMENT 3}

The previous studies leave little doubt that a negative contrast effect will occur with a second or third downshift in sucrose concentration after the animals have been returned for several days to the original $32 \%$ concentration. Experiment 3 was concerned with exploring the limits of contrast with repeated shifts. 
Specifically, would negative contrast occur repeatedly if the animals were shifted every other day between $32 \%$ and $4 \%$ sucrose? Would the degree of contrast diminish with increasing numbers of shifts? Would positive contrast occur with repeated shifts?

Two groups of shifted animals were run, one shifted on a single alternation schedule and one shifted on a double alternation schedule. In addition, one control group was employed for positive contrast and another was employed for negative contrast.

\section{Method}

Subjects. Twenty naive male rats of the Sprague-Dawley strain were used as subjects. The animals were approximately 80 days old at the start of the experiment and individually housed under a 14/10-h light/dark cycle. The rats were maintained at $82 \%$ of their free-feeding body weights throughout the experiment. Water was available continuously.

Procedure. The subjects were divided into four groups. One group received a $4 \%$ sucrose solution throughout the experiment while another group had access to $32 \%$ sucrose for the entire experiment. The remaining groups received both solutions on alternating schedules. One of these groups received $32 \%$ and $4 \%$ sucrose on alternating days $(32-4)$, and the other group had access for 2 days to each of the solutions, on an alternating basis $(32,32,4,4)$.

On each day, the subjects were given access to the appropriate sucrose solution, for $5 \mathrm{~min}$, starting from the first lick. Except for the $32-4$ group, all groups were run for 22 days. Due to experimental error, Group 32-4 was terminated after 19 days. On any day, groups that were receiving $4 \%$ sucrose were run before groups that were receiving $32 \%$ sucrose. This was done as a precautionary measure against spillage of the solutions. Sucrose solutions were prepared by weight (sucrose/sucrose + water) from commercial-grade cane sugar and tap water, $24 \mathrm{~h}$ before each session.

\section{Results}

The results obtained with the single-shift animals are presented in Figure 4, and those obtained with the double-shift animals are presented in Figure 5. It is

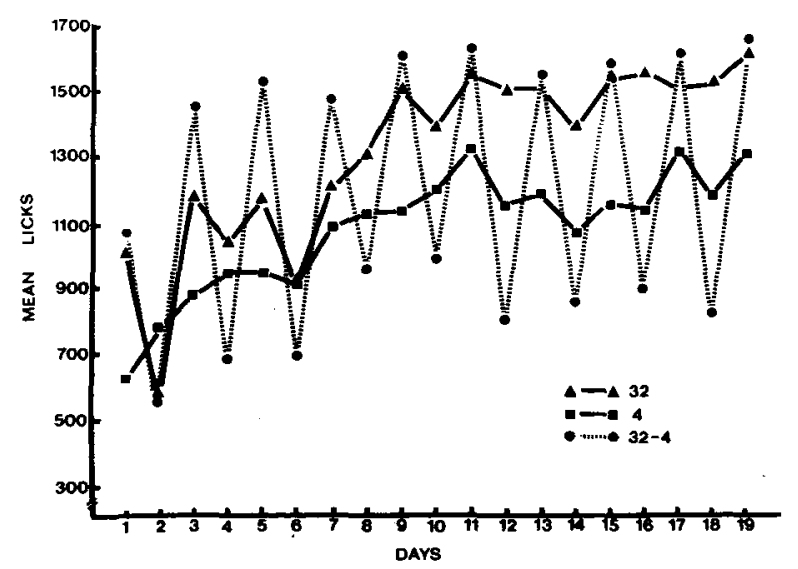

Figure 4. Lick frequency as a function of sucrose condition in animals shifted between $32 \%$ and $4 \%$ sucrose on alternate days (Group $32-4$ ) and in animals maintained on either $32 \%$ or $4 \%$ sucrose.

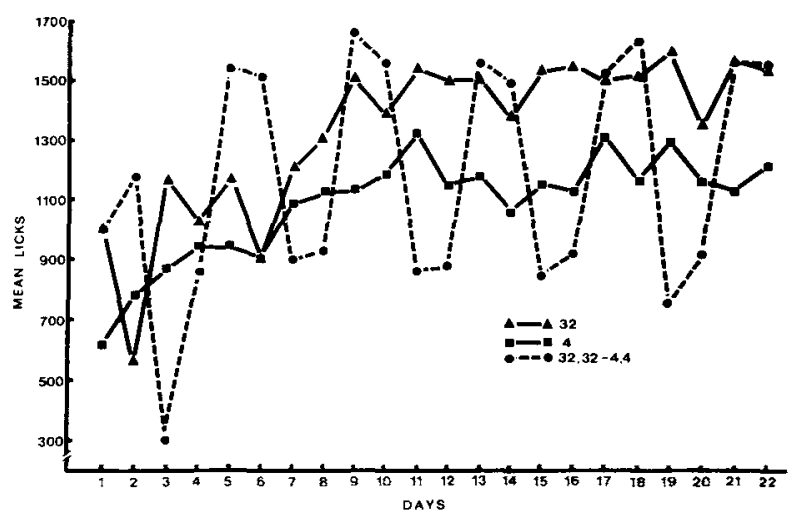

Figure 5. Lick frequency as a function of sucrose condition in animals shifted every 2 days between $32 \%$ and $4 \%$ sucrose, and in unshifted animals.

immediately apparent that repeated negative contrast occurred in both single- and double-shift groups and that this contrast did not diminish with repeated shifts. It is also apparent that positive contrast tended to occur in the early shifts, but that this contrast diminished as the lick rate of the $32 \%$ control group increased across days. There was no apparent difference in degree of contrast in the single- and double-shift groups. Some of these effects may be clearer in Figures 6 and 7, in which the data are the same as those in Figures 4 and 5, except that they are plotted in terms of shift number and the lick rates obtained under like sucrose conditions are connected.

Analysis of variance of the single-alternation negativecontrast data indicated reliable contrast $[F(1,8)=17.15$, $p<.01]$ and no interaction of contrast with days $(F=1.00)$. Thus, degree of negative contrast remained unchanged across the repeated shifts. Analysis of the single-shift positive-contrast data indicated a reliable overall positive contrast effect $[F(1,6)=7.67, p<.05]$. Although the contrast $X$ day interaction was not statistically reliable $[F(8,48)=1.52, p>.15]$, an 1sd test $(p=.05)$ indicated that the positive contrast was reliable in the first three shifts.

Analysis of the double-shift negative-contrast data indicated a marginal overall negative contrast effect $[F(1,7)=5.12, p<.058]$ and a reliable contrast $X$ shift $X$ day effect $[F(4,28)=3.23, p=.05]$. Analysis of the latter term with the 1sd test (using pooled error termWiner, 1962) indicated the following. Negative contrast was greater on the 1st postshift day than on the 2 nd postshift day. This negative contrast was reliable on the 1st postshift day in the first, third, fourth, and fifth shifts. A reliable negative-contrast effect occurred on the 2nd postshift day only during the third shift. Thus, these data indicated that contrast remained relatively stable with repeated shifts, but did tend to recover on the 2 nd postshift day of each of the shifts in the double-alternation group. 


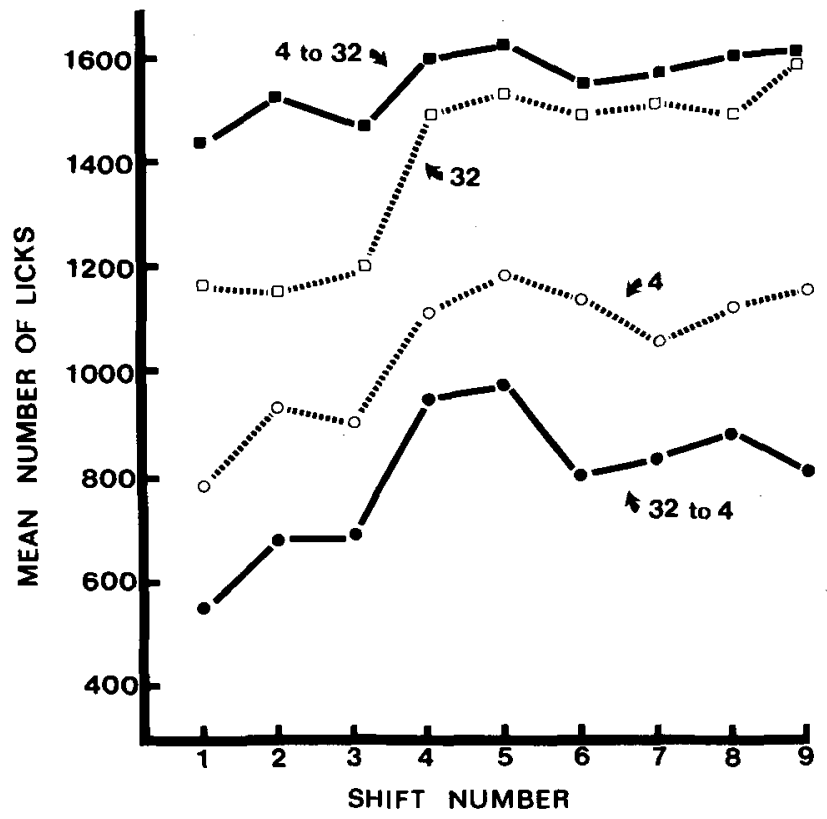

Figure 6. The same data as Figure 4 plotted as a function of shift number. The difference between Groups 4 and 32-4 represents a negative contrast effect; the difference between Groups 32 and $\mathbf{4 - 3 2}$ represents a positive contrast effect.

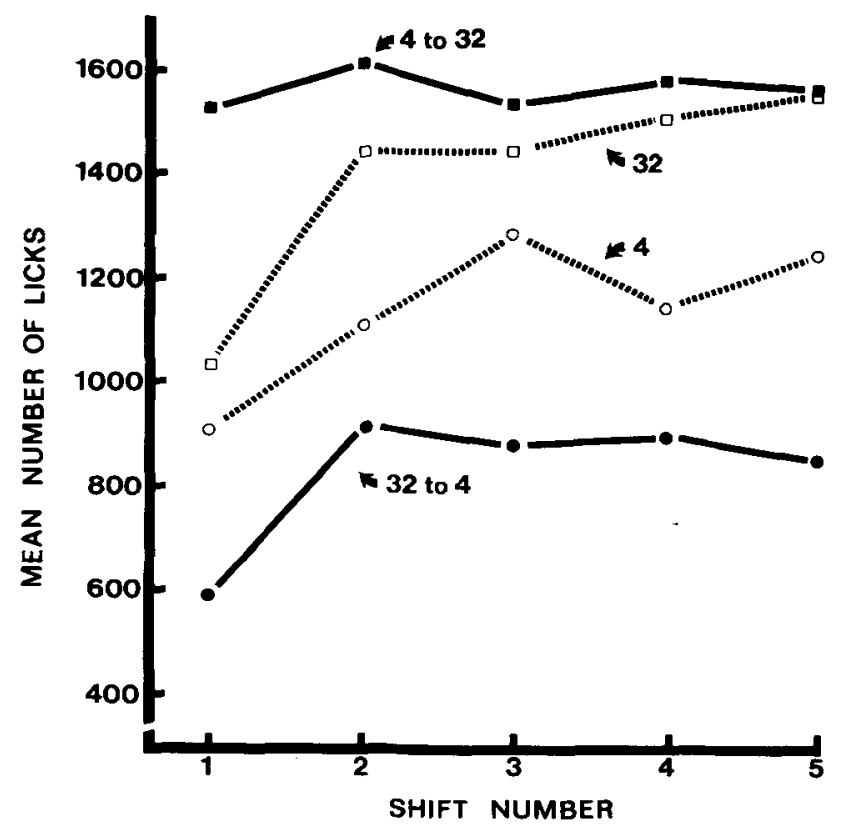

Figure 7. Same data as in Figure 5 plotted as a function of shift number. The difference between Group 4 and Group 32-4 represents a negative contrast effect; the difference between Group $4-32$ and Group 32 represents a positive contrast effect.

Analysis of the positive-contrast data indicated a reliable contrast $X$ shift effect $[F(5,25)=2.71, p<.05]$, and further analysis with the lsd test indicated that positive contrast was reliable in the first two shifts only.

\section{Discussion}

These data show that negative-contrast effects obtained with repeated daily shifts are robust and enduring, as are negative contrast effects when the animals are given 2 days' experience with each sucrose condition prior to the shift. In the latter case, some recovery from contrast was evident on the 2nd postshift day throughout the cycle of repeated shifts. Positive contrast occurs only during the initial shifts, but the reduction in positive contrast with repeated shifts appears to be due to enhanced lick rates in the control animals rather than a reduction in the effect of the shift from $4 \%$ to $32 \%$ sucrose. In other words, positive contrast may be limited by the ceiling-effect problem (cf. Mellgren, 1972; Shanab, Sanders, \& Premack, 1969).

\section{GENERAL DISCUSSION}

The results of these experiments show that successive negative contrast in consummatory behavior will occur repeatedly with repeated shifts in sucrose concentration. These repeated contrast effects were found under several different experimental procedures. These included the open-field versus more typical testing conditions and differential amounts of time spent with the preshift solution after the first shift-1, 2, 6, 8, and 10 days in the different experiments. The occurrence of repeated negative contrast under these diverse conditions, and its failure to diminish in degree with repeated shifts in Experiment 3, is an indication of the robustness of contrast in this paradigm.

The results are particularly relevant to reinforcement level and emotional interpretations of incentive contrast. The reinforcement-level theory (Capaldi, 1974) states that contrast is due to a discrepancy from an average, or expected, level of reinforcement. There are substantial data which show that animals average different levels of reward received in the past and that degree of contrast is a function of degree of discrepancy from this average level of reward (Flaherty, Becker, \& Osborne, in press; McHose \& Peters, 1975). The failure of negative contrast to diminish substantially with repeated shifts in any of these experiments indicates that the expected reward level is quickly "reset" to the maximum value when animals are returned to the preshift reward. That is, if the animals developed an expectancy of the average sucrose concentration received in the situation, then contrast would be expected to diminish as they experienced the two solutions and developed an average value (Flaherty et al., in press). Thus, a period of $5 \mathrm{~min}$ on alternate days must be sufficient to maintain reinforcement level at the largest value experienced, at least in the case of the parameters used in the present experiments.

The results are also relevant to an interpretation of successive negative contrast in terms of emotional responses elicited by the reward reduction. There have been many suggestions that frustration is causally related to the behavioral decrements that occur when reward 
level is shifted down (e.g., Bower, 1961;Cleland, Williams, \& DiLollo, 1969; Crespi, 1942, 1944; Spence, 1956). There is also substantial circumstantial evidence that supports such an interpretation. For example, successive negative contrast effects are reduced by drugs that have anxiolytic actions in humans, such as chlordiazepoxide (Flaherty et al., 1980; Rosen \& Tessel, 1970; Vogel \& Principi, 1971), sodium amobarbital (Flaherty, Becker, \& Driscoll, 1982; Flaherty \& Driscoll, 1980), and ethanol (Becker \& Flaherty, 1982), as well as combinations of ethanol and chlordiazepoxide (Becker \& Flaherty, 1983). Similar drug effects have been obtained in negative behavioral contrast (e.g., Ridgers \& Gray, 1973). Drugs that have other than anxiolytic properties may not reduce contrast. This has been the case with the neuroleptics chlorpromazine (Roberts \& Pixley, 1965; Rosen \& Tessel, 1970; Flaherty, Driscoll, \& Checke, Note 1) and haloperidol (Flaherty, Becker, Actor, \& McCurdy, Note 2), the anticholinergic scopolamine (Flaherty \& Meinrath, 1979), and the serotonin antagonist methysergide (Becker \& Flaherty, Note 3). Thus, the pharmacological evidence is consistent with an interpretation of successive negative contrast in terms of an emotional response being causally related to the behavior.

Additional support is derived from evidence of a relationship between other aversive situations such as delay of reward (e.g., Daly, 1974), contrast (Shanab \& Ferrell, 1975), and punishment and contrast (Rossellini \& Terris, 1975). Also, the increases in ambulation and rearing found in Experiment 1 and in other studies (e.g., Flaherty et al., 1978; Flaherty, Powell, \& Hamilton, 1979; Flaherty, Troncoso, \& Deschu, 1979) correspond to behavior changes that factor load on an emotional reactivity dimension in mice (Royce, Poley, \& Yeudall, 1973).

Finally, to the extent that the negative-contrast effects reported here are related to extinction (cf. Gonzalez, Fernhoff, \& David, 1973) and negative behavioral contrast, an emotionality interpretation is favored by the findings of increased corticosteroid release found in these latter situations (Dantzer, Arnone, \& Mormede, 1980; Goldman, Coover, \& Levine, 1973).

However, if emotional responses are causally related to contrast, one might ask if such responses remain unabated with frequent shifts in reward (degree of contrast itself did not diminish with such shifts). It is not immediately obvious what adaptive value such unassuageable emotional behavior would have, particularly if the full panoply of sympathetic activation accompanies each downshift. However, it is possible that the consummatory paradigm is particularly sensitive to negative contrast, a possibility consistent with the observation that contrast will occur in consummatory behavior but not in runway behavior when both are measured in the runway context (Flaherty \& Caprio, 1976). If this is the case, then consummatory contrast may occur under conditions that are minimally aversive to the animal, and, thus, there may be no major sympathetic activation with each downshift. It could be that the role of frustration in the repeated contrast effect is similar to the apparent role of fear in avoidance behavior. That is, fear apparently diminishes from the acquisition to the maintenance stage of avoidance performance (Kamin, Brimer, \& Black, 1963; Mineka, 1979; Starr \& Mineka, 1977 ) and yet avoidance continues at a high level. Possibly, frustration is particularly likely to occur during the initial shifts, but then, with repeated shifts, the causal mechanism becomes more cognitive than emotional. Some evidence in this regard might be obtained from measures of corticosteroid levels at different shift stages, from the effects of anxiolytic drugs at different shift cycles, and/or from some measure of conditioned frustration such as that used by Daly (e.g., Daly, 1974).

\section{REFERENCE NOTES}

1. Flaherty, C. F., Driscoll, C., \& Checke, S. A comparison of the effects of several drugs on successive contrast. Paper presented to the meeting of the Eastern Psychological Association, New Haven, 1980.

2. Flaherty, C. F., Becker, H. C., Actor, J., \& McCurdy, M. L. A comparsion of the effects of anxiolytics, neuroleptics, and an antidepressant on successive negative contrast. Paper presented to the meeting of the Eastern Psychological Association, Philadelphia, 1983.

3. Becker, H. C., \& Flaherty, C. F. Effects of serotonin antagonists methysergide and cyproheptadine on negative contrast. Paper presented at the annual meeting of the Psychonomic Society, San Diego, 1983.

\section{REFERENCES}

Becker, H. C., \& Flaherty, C. F. Influence of ethanol on contrast in consummatory behavior. Psychopharmacology, 1982, 77, 253-258.

Becker, H. C., \& Flaherty, C. F. Chlordiazepoxide and ethanol additively reduce gustatory negative contrast. Psychopharmacology, 1983, 80, 35-37.

Bevan, W. The contextual basis of behavior. American Psychologist, 1968, 23, 701-713.

Bower, G. H. A contrast effect in differential conditioning. Journal of Experimental Psychology, 1961, 62, 196-199.

Capaldr, E. J. Partial reward either following or preceding consistent reward: A case of reinforcement level. Journal of Experimental Psychology, 1974, 102, 954-962.

CaPAldi, E. J., \& LYNCh, D. Repeated shifts in reward magnitude: Evidence in favor of an associational and absolute (noncontextual) interpretation. Journal of Experimental Psychology, $1967,75,226-235$.

Cleland, E. A., Williams, M. Y., \& DiLollo, V. Magnitude of negative contrast effect in relation to drive level. Psychonomic Science, 1969, 15, 121-122.

Crespi, L. P. Quantitative variation in incentive and performance in the white rat. American Journal of Psychology, 1942, 55, 467-517.

Crespi, L. P. Amount of reinforcement and level of performance. Psychological Review, 1944, 51, 341-357.

DaLY, H. B. Reinforcing properties of escape from frustration. In G. H. Bower, (Ed.), The psychology of learning and motivation. New York: Academic Press, 1974.

Dantzer, R., Arnone, M., \& Mormede, P. Effects of frustration on behavior and plasma corticosteroid levels in pigs. Physiology \& Behavior, 1980, 24, 1-4. 
Flaherty, C. F. Incentive contrast: A review of behavioral changes following shifts in reward. Animal learning \& Behavior, $1982,10,409-440$.

Flahenty, C. F., Becken, H. C., \& Driscoll, C. Conditions under which amobarbital sodium influences contrast in consummatory behavior. Physiological Psychology, 1982, 10, 122-128.

Flaherty, C. F., Becker, H. C., \& Osborne, M. Negative contrast following regularly increasing concentrations of sucrose solutions: Rising expectations or incentive averaging? Physiological Record, in press.

FLaherty, C. F., Blitzer, R., \& Collier, G. H. Open field behaviors elicited by reward reduction. American Journal of Psychology, 1978, 91, 429-443.

Flahe RTY, C. F., \& Caprio, M. Dissociation between instrumental and consummatory measures of incentive contrast. American Journal of Psychology, 1976, 89, 485-498.

Flaherty, C. F., \& Driscoll, C. Amobarbital sodium reduces successive gustatory contrast. Psychopharmacology, 1980, 69, 161-162.

Flaherty, C. F., Lombardi, B. R., Wrightson, J., \& Deptula, D. Conditions under which chlordiazepoxide influences gustatory contrast. Psychopharmacology, 1980, 67, 269-277.

Flaherty, C. F., \& Meinrath, A. B. Influence of scopolamine on sucrose intake under absolute and relative test conditions. Physiological Psychology, 1979, 7, 412-418.

Flahe rty, C. F., Poweld, G., \& Hamilton, L. W. Septal lesion, sex, and incentive shift effects on open field behavior of rats. Physiology \& Behavior, 1979, 22, 903-909.

Flaherty, C. F., Riley, G. A., \& Spear, N. E. Effect of sucrose concentration and goal units on runway behavior in the rat. Learning and Motivation, 1973, 4, 163-175.

Flaherty, C. F., Troncoso, B., \& Deschu, N. Open field behaviors correlated with reward availability and reward shift in three rat strains. American Journal of Psychology, 1979, 92, $385-400$

Goldman, L., Coover, G. D., \& Levine, S. Bidirectional effects of reinforcement shifts on pituitary adrenal activity. Physiology \& Behavior, 1973, 10, 209-214.

Gonzalez, R. C., Fernhoff, D., \& David, E. G. Contrast, resistance to extinction, and forgetting in rats. Journal of Comparative and Physiological Psychology, 1973, 84, 562-571.

Goomas, D. T. Multiple shifts in magnitude of reward. Psychological Reports, 1981, 49, 335-338.

Kamin, L. J., Brimer, C. J., \& Black, A. H. Conditioned suppression as a monitor of fear of the CS in the course of avoidance training. Journal of Comparative and Physiological Psychology, 1963, 56, 497-501.

Maxwell, F. R., Calef, R. S., Murkay, D. W., Shepard, J. C., \& Norville, R. A. Positive and negative successive contrast effects following multiple shifts in reward magnitude under high drive and immediate reinforcement. Animal Learning \& Behavior, 1976, 4, 480-484.

McCain, G., \& Cooney, J. PCE I. The effects of three reward magnitude shifts. Bulletin of the Psychonomic Society, 1975, 6, 523-526.

McCain, G., Lobb, M., Almand, W., \& Leck, D. Delay of reinforcement: Extended training and multiple shifts. Bulletin of the Psychonomic Society, 1976, 7, 539-541.
McCain, G., Lobb, M., \& NewberRy, J. Extended training and multiple shifts: Percentage of reward. Bulletin of the Psychonomic Society, 1976, 8, 191-193.

McHose, J. H., \& Peters, D. P. Partial reward, the negative contrast effect, and incentive averaging. Animal Learning \& Behavior, 1975, 3, 239-244.

MeinRATH, A. B. The role of neophobia in successive negative contrast: Effects of early handling and varied taste exposure. Unpublished doctoral dissertation, Rutgers University, 1980.

Mellaren, R. L. Positive and negative contrast effects using delayed reinforcement. Learning \& Motivation, 1972, 3, 185-193.

Mine KA, S. The role of fear in theories of avoidance learning, flooding, and extinction. Psychological Bulletin, 1979, 86, 985-1010.

Ridgers, A., \& Gray, J. A. Influence of amylobarbitone on operant depression and elation effects in the rat. Psychopharmacologia, 1973, 32, 265-270.

Roberts, W. A., \& Pixley, L. The effects of chlorpromazine on the depression effect, Psychonomic Science, 1965, 3, 407-408.

Rosellini, R. A., \& Terris, W. Incentive shift in the rat following training to resist punishment. Learning \& Motivation, 1975, $6,421-438$

Rosen, A. J., \& Tessel, R. E. Chlorpromazine, chlordiazepoxide, and incentive shift performance in the rat. Journal of Comparative and Physiological Psychology, 1970, 72, 257-262.

Royce, J. R., Poley, W., \& Yeudall, L. T. Behavior-genetic analysis of mouse emotionality: I. Factor analysis. Journal of Comparative and Physiological Psychology, 1973, 83, 36-47.

Shanab, M. E., Domino, J., \& Melrose, S. The effects of shifts in delay of liquid sucrose reward in thirsty rats. Bulletin of the Psychonomic Society, 1977, 10, 287-290.

Shanab, M. E., \& FerReld, H. J. Transfer between downshift in reward magnitude and continuous delay of reward. Learning and Motivation, 1975, 6, 241-252.

Shanab, M. E., France, J., \& Young, T. Negative contrast effects obtained with downshifts in magnitude but not concentration of solid sucrose reward. Bulletin of the Psychonomic Society, $1975,5,429-432$.

Shanab, M. E., Sanders, R., \& Premack, D. Positve contrast in the runway obtained with delay of reward. Science, 1969, 164, 724-725.

Spence, K. W. Behavior theory and conditioning. New Haven: Yale University Press, 1956.

StarR, M. D., \& Mineka, S. Determinants of fear over the course of avoidance learning. Learning and Motivation, 1977, $8,332-350$

Vogel, J. R., Mikulka, P. J., \& Spear, N. E. Effects of shifts in sucrose and saccharine concentrations on licking behavior in the rat. Journal of Comparative \& Physiological Psychology, $1968,66,661-666$.

Vogel, J. R., \& Principi, K. Effects of chlordiazepoxide on depressed performance after reward reduction. Psychopharmacologia, 1971, 21, 8-12.

WINER, B. J. Statistical principles in experimental design. New York: McGraw-Hill, 1962.

(Manuscript received March 28, 1983; revision accepted for publication July $25,1983$. 